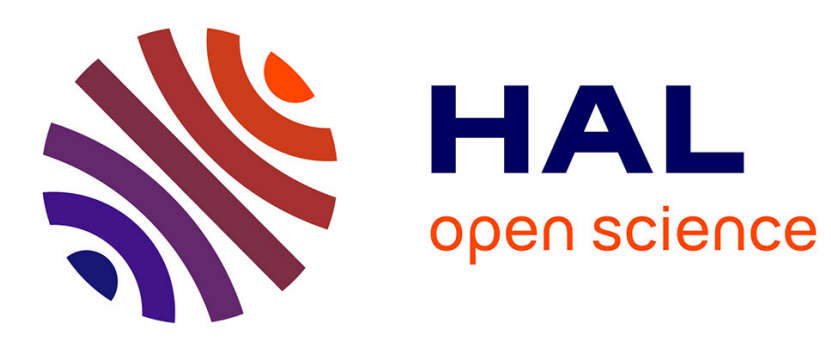

\title{
CO2 adsorption on calcium oxide: An atomic-scale simulation study
}

Rémy Besson, Mateus Rocha Vargas, Loïc Favergeon

\section{To cite this version:}

Rémy Besson, Mateus Rocha Vargas, Loïc Favergeon. CO2 adsorption on calcium oxide: An atomicscale simulation study. Surface Science: A Journal Devoted to the Physics and Chemistry of Interfaces, 2012, 606 (3-4), pp.490-495. 10.1016/j.susc.2011.11.016 . hal-00657354

\section{HAL Id: hal-00657354 https://hal.science/hal-00657354}

Submitted on 6 Jan 2012

HAL is a multi-disciplinary open access archive for the deposit and dissemination of scientific research documents, whether they are published or not. The documents may come from teaching and research institutions in France or abroad, or from public or private research centers.
L'archive ouverte pluridisciplinaire HAL, est destinée au dépôt et à la diffusion de documents scientifiques de niveau recherche, publiés ou non, émanant des établissements d'enseignement et de recherche français ou étrangers, des laboratoires publics ou privés. 


\title{
$\mathrm{CO}_{2}$ adsorption on calcium oxide: an atomic-scale simulation study
}

R. Besson ${ }^{\mathrm{a}, *}$, M. Rocha Vargas ${ }^{\mathrm{b}, \mathrm{c}}$, L. Favergeon ${ }^{\mathrm{b}}$

${ }^{a}$ Unité Matériaux et Transformations, CNRS UMR 8207, Université de sciences et technologies de Lille, F-59655 Villeneuve d'Ascq, FRANCE

${ }^{\mathrm{b}}$ Laboratoire des Procédés en Milieux Granulaires - CNRS FRE 3312, Centre SPIN - Ecole

Nationale Supérieure des Mines de Saint-Etienne, FRANCE

${ }^{\mathrm{c}}$ Departamento de Engenharia Quimica, Instituto Superior Técnico, Av. Rovisco Pais $\mathrm{n}^{\circ} 1$, 1049-001 Lisboa, PORTUGAL

\begin{abstract}
We present a detailed study of $\mathrm{CO}_{2}$ adsorption on $\mathrm{CaO}$, by means of atomic-scale simulations relying on Density Functional Theory. Combining ab initio thermodynamics of the $\mathrm{CO}_{2}$ gas phase and a thorough analysis of its interaction with the oxide, we build an orientationsensitive adsorption model, which demonstrates that low coverage by the gas is expected in a wide range of working conditions, including the domain of stability of $\mathrm{CaCO}_{3}$ calcite. Investigation of the interactions between the adsorbed molecules reinforces this conclusion. Our work thus provides a strong hint that calcite nucleation should occur by a localised mechanism, discarding the possibility of collective surface transformation.
\end{abstract}

\section{Introduction}

Reducing the amount of $\mathrm{CO}_{2}$ emitted by power plants or large industrial combustion sources is an important environmental and scientific issue. To this aim, $\mathrm{CaO}$-based sorbents allow separation and capture of $\mathrm{CO}_{2}$ from fuels and flue gases as well as $\mathrm{CO}_{2}$ capture from ambient air [1], thus offering a possible route towards the desired stabilization of $\mathrm{CO}_{2}$ concentration in the atmosphere. The process consists of a series of cycles where $\mathrm{CaO}$ is transformed into $\mathrm{CaCO}_{3}$ in a carbonation reactor, and then calcination of $\mathrm{CaCO}_{3}$ in a decarbonation reactor allows to regenerate the sorbent and to produce a concentrated stream of $\mathrm{CO}_{2}$ suitable for disposal. However, a major practical difficulty stems from the significant degradation of performance in $\mathrm{CO}_{2}$ capture [2, 3] when increasing the number of carbonation/decarbonation cycles, and several studies have already been carried out in order to explain this detrimental effect. In this context, while the $\mathrm{CaCO}_{3}$ decarbonation reaction has been extensively studied [4-8], only few works deal with a comprehensive understanding of $\mathrm{CaO}$ carbonation, whereas this process may have important consequences, not only for the 
capture of environmental $\mathrm{CO}_{2}$, but also for various other issues such as $\mathrm{CaO}$-containing minerals in underground locations or biogenic $\mathrm{CaCO}_{3}$ formation.. Bathia et al. [9] have proposed a mechanism of growth in elementary steps for $\mathrm{CaO}$ carbonation, but without inferring a rate law satisfactorily modelling the reaction trends. Rouchon et al. [10] have performed a kinetic study in order to precise the link between the carbonation rate and the porosity structure of the $\mathrm{CaO}$ aggregates. They have shown that the reaction involves a slow surface nucleation process followed by the growth of the nuclei, the hypothesis of nucleation being supported by the observation of an induction period at the beginning of the reaction. During solid-gas reactions, the nucleation process often involves several elementary steps. In the case of $\mathrm{CaO}$ carbonation, the first step should consist of the adsorption of $\mathrm{CO}_{2}$ molecules on the $\mathrm{CaO}$ surface, and it is therefore of primary interest to reach a better understanding of this phenomenon.

Only few works have studied the interaction of $\mathrm{CO}_{2}$ with $\mathrm{CaO}$ surfaces. Voigts et al [11] have used Metastable Induced Electron Spectroscopy (MIES) together with Ultraviolet and X-ray Photoelectron Spectroscopy data (UPS and XPS) to investigate the adsorption of $\mathrm{CO}_{2}$ on $\mathrm{CaO}$ films under ultrahigh vacuum conditions. This study suggests that no $\mathrm{CO}_{2}$ dissociation occurs on the $\mathrm{CaO}(100)$ surface, and that the O-C-O bonding angle decreases to about $130^{\circ}$, in agreement with prior studies $[12,13]$. The MIES spectra led to the assumption that the whole $\mathrm{CaO}$ surface is covered with $\mathrm{CO}_{2}$, the XPS data showing the formation of $\mathrm{CO}_{3}{ }^{2-}$ complexes throughout the (100) surface. As part of an experimental and theoretical work on the same system [14], Density Functional Theory (DFT) simulations allowed to conclude that the most stable adsorption configuration of $\mathrm{CO}_{2}$ occurs, as expected, via the $\mathrm{C}$ atom which is adsorbed on $\mathrm{O}$ sites of $\mathrm{CaO}$, therefore confirming the existence of $\mathrm{CO}_{3}{ }^{2-}$ complexes. No adsorption takes place via the $\mathrm{O}$ atoms or on $\mathrm{Ca}$ sites. The calculations were performed on $\mathrm{Ca}_{\mathrm{x}} \mathrm{O}_{\mathrm{x}}$ clusters, taking into account that adsorption may occur either on terrace, edge or corner sites. This study also allowed to acknowledge that the molecule may be linked to the cluster with an angle of either $0^{\circ}$ or $45^{\circ}$, with respect to the $\langle 100\rangle$ atomic rows within the (100) surface.

In this context, the present work is devoted to a thorough atomic-scale analysis of $\mathrm{CO}_{2}$ adsorption on the surface of $\mathrm{CaO}$. Its main purpose will be to investigate issues that have been generally overlooked in previous studies, in particular the way of using atomic-scale energy calculations in order to achieve a quantitative assessment of the adsorption properties. To this aim, we will consider with special detail the thermodynamic modeling of adsorption. As a second original feature, attention will be paid to the role of interactions between adsorbed 
molecules, an intricate task seldom investigated at the atomic scale. Whereas efficient available empirical potentials for $\mathrm{CaO}[15]$ and $\mathrm{CaCO}_{3}[16,17]$ might a priori be convenient tools for our goal, this would require to design additional empirical interactions between the oxide and the gas. Due to this severe practical difficulty, ab initio calculations based on DFT were preferred in this work, with pseudopotentials ensuring the required transferability to various environments (gas and adsorption). After a preliminary part dealing with the thermodynamics of $\mathrm{CO}_{2}$ gas and a comparison of $\mathrm{CaO}$ clean surfaces, we focus on the elaboration of an adsorption model following two successive steps: (i) adsorption considering non-interacting adsorbed $\mathrm{CO}_{2}$ molecules and (ii) role of lateral interactions between molecules. Our work finally provides arguments related to the practically important issue of carbonate nucleation.

\section{Methodological background}

\subsection{Ab initio calculations}

The required DFT calculations were performed with the Vienna Ab initio Simulation Package (VASP) [18, 19], using the Projector Augmented Wave (PAW) method. The Generalized Gradient Approximation (GGA) was employed with the Perdew-BurkeErnzerhof (PBE) functional [20, 21]. The plane wave expansions of Kohn-Sham orbitals were truncated at a cut-off energy of $600 \mathrm{eV}$. With a $4 \times 4 \times 4 \mathrm{k}$-mesh for a $\mathrm{CaO}$ unit cell, these values were found sufficient throughout to ensure the convergence of total energies within 1 meV.atom ${ }^{-1}$. All bulk calculations included relaxations for ionic positions as well as lattice vectors, while surface calculations were performed keeping fixed supercell (SC) dimensions within the surface plane. In presence of adsorbed $\mathrm{CO}_{2}$, special attention had to be paid to the realistic determination of the optimal height of the molecule above the surface plane, since slight variations for the initial value of this parameter were found to lead to significantly different energies.

\subsection{Modeling of $\mathrm{CO}_{2}$ gas}

In the pressure and temperature ranges considered here (see section 3.3), the $\mathrm{CO}_{2}$ gas phase may reasonably be considered as perfect. The partition function for a gas with $\mathrm{N}$ identical non-interacting molecules is $z=z^{N} /{ }_{N !}$, where $z=z_{0} \zeta(\beta)$ is the partition 
function of a single molecule. Here, $\zeta(\beta)$ is the partition function for the internal structure of the molecule and $\mathrm{z}_{0}$ the partition function of its translational movement:

$$
z_{0}=V\left(\frac{m}{\beta 2 \pi \hbar^{2}}\right)^{3 / 2}
$$

where $\beta=1 / k_{B} T, V$ is the volume of the gas, $m$ the mass of the $\mathrm{CO}_{2}$ molecule and $\hbar$ the reduced Planck constant. The partition function associated with the internal structure of the molecule is $\zeta(\beta)=\zeta_{\beta} \zeta_{r} \zeta_{v}$, where $\zeta_{e}, \zeta_{r}$ and $\zeta_{v}$ are the electronic, rotational and vibrational partition functions. The first two terms are given by $\zeta_{e}=g_{0} e^{\beta \varepsilon_{\circ}}$ and $\zeta_{r}=2 \mathrm{I} / \sigma \hbar \beta$, where $\varepsilon_{0}$ is the ground-state energy of the molecule, $\mathrm{g}_{0}$ its degeneracy, $\sigma$ a symmetry factor ( 2 for a linear symmetrical molecule), and $I$ the moment of inertia. The vibrational part is:

$$
\zeta_{v}=\prod_{i=1}^{4} \frac{1}{2 \operatorname{sh}\left(\beta \pi \omega_{i} / 2\right)}
$$

$\left\{\omega_{i}\right\}$ being the four vibrational frequencies of the molecule (one degenerate bending mode and two stretching modes). The $\mathrm{CO}_{2}$ vibration frequencies were deduced from the ab initio analysis of the force constants, the latter being determined by applying displacements on the equilibrium configurations of the molecule. The magnitude of the displacements was selected as $0.1 \AA$, ensuring the required linear behavior of the atomic forces.

From the free energy $F=-\frac{1}{\beta} \ln Z$, the chemical potential for the $\mathrm{CO}_{2}$ gas is readily obtained:

$$
\mu_{C O_{2}}=\frac{\partial F}{\partial N}=-\frac{1}{\beta} \ln \frac{z}{N}=-\frac{1}{\beta} \ln \left[\frac{\beta(\beta)}{\beta p}\left(\frac{2 \pi \beta \hbar^{2}}{m}\right)^{3 / 2}\right]
$$

\subsection{Adsorption models}

Models describing the adsorption of $\mathrm{CO}_{2}$ on $\mathrm{CaO}$ are most conveniently built using the grand canonical (GC) framework [22], namely by considering the equilibrium between the atoms adsorbed on the surface and a reservoir of particles and energy (surrounding gas) which imposes a given temperature and $\mathrm{CO}_{2}$ chemical potential. In the present case, this requires taking into account (i) the two non-equivalent orientations of adsorbed $\mathrm{CO}_{2}$, and (ii) the twofold symmetry degeneracy of these orientations. In the following, type 1 (resp. type 2) 
therefore refers to $\mathrm{CO}_{2}$ orientations of $0^{\circ}$ or $90^{\circ}$ (resp. $45^{\circ}$ or $135^{\circ}$ ). Neglecting first the lateral interactions between the adsorbed molecules (Independent Point Defect Approximation IPDA) leads to a simple additive form for the energy of the solid-gas system:

$$
E_{a}^{I P D A}\left(N_{1}, N_{2}\right)=E_{\text {ref }}+E_{1}^{G C} N_{1}+E_{2}^{G C} N_{2}
$$

with $E_{r e f}$ the reference energy of the clean surface, $\left(N_{1}, N_{2}\right)$ the numbers of particles adsorbed for both types of orientations and $\left(E_{1}^{G C}, E_{2}^{G C}\right)$ the corresponding GC energies. In the GC formalism, the equilibrium is characterized by the minimum, with respect to $\left(N_{l}, N_{2}\right)$, of the partial GC partition function:

$$
\tilde{Z}^{G C}=\Omega\left(N_{1}, N_{2}\right) e^{-\beta\left(E_{a}-\left(N_{1}+N_{2}\right) \mu_{C O}\right)}
$$

with $\Omega\left(N_{1}, N_{2}\right)=2^{N_{1}} 2^{N_{2}} C_{N_{s}}^{N_{1}} C_{N_{s}-N_{1}}^{N_{2}}$, the number of microscopic states, accounting for the degeneracy of each type of orientation. Under the assumption of non-interacting adsorbed molecules, the surface coverage $\theta_{i}=N_{i} / N_{s}$ ( $N_{s}=$ total number of available surface sites $)$ is thus given by:

$$
\frac{\theta_{1}}{2\left(1-\theta_{1}-\theta_{2}\right)}=e^{-\beta\left(E_{1}^{G C}-\mu_{C O}\right)} \quad \frac{\theta_{2}}{2\left(1-\theta_{1}-\theta_{2}\right)}=e^{-\beta\left(z_{2}^{G C}-\mu_{2} C O_{2}\right)}
$$

Modeling the interactions between the adsorbed molecules is an extremely intricate task since, strictly speaking, the latter are configuration-dependent. In order to preserve tractability and realistic modelling, we thus adopted a correction term for the energy of the adsorbed molecules:

$$
E_{a}\left(N_{1}, N_{2}\right)=E_{a}^{I P D A}\left(N_{1}, N_{2}\right)+N \delta E^{I P D A}\left(\theta_{1}, \theta_{2}\right)
$$

where $\delta E^{I R D A}\left(\theta_{1}, \theta_{2}\right)$ describes the deviation from IPDA and $N=N_{3} / 2$ the number of sites on the surface. Modifying accordingly the GC partition, equation (5), as:

$$
\tilde{Z}^{G C}=\tilde{Z}^{G C}(I P D A) e^{-\beta N E E^{I P D A}\left(\theta_{1}, \theta_{2}\right)}
$$


leads to the interaction-dependent coverage rates as solutions of the following non linear system of equations $(i=1$ or 2$)$ :

$$
\frac{\theta_{i}}{2\left(1-\theta_{1}-\theta_{2}\right)}=e^{-\beta\left(E_{i}^{C C}-\mu_{C O_{2}}+\frac{1}{2} \frac{B \sigma E^{I P D A}}{B \theta_{i}}\right)}
$$

\section{Results and discussion}

\section{1 $\mathrm{CO}_{2}$ gas and $\mathrm{CaO}-\mathrm{CaCO}_{3}$ equilibrium}

Table 1 presents the vibrational frequencies for the isolated $\mathrm{CO}_{2}$ molecule (ground state energy of $-22.943 \mathrm{eV}$ ) obtained from the present ab initio calculations, together with values for these quantities retrieved from earlier works [22-24]. The agreement is good, which provides a reasonable hint of the validity of the present DFT calculations for the $\mathrm{CO}_{2}$ gas phase. From equation (6), Figure 1 displays the chemical potential $\mu_{\mathrm{CO}_{2}}$ as a function of temperature up to $1000 \mathrm{~K}$, for a wide range of pressures between $0.5 \mathrm{kPa}$ and $100 \mathrm{kPa}$, showing variations of $\sim 3 \mathrm{eV}$ in this domain. Performing this full thermodynamic analysis of $\mathrm{CO}_{2}$ is required to evaluate $\mu_{C O_{2}}$ in the relevant $(\mathrm{P}, \mathrm{T})$ conditions, in a way both sufficiently realistic and consistent with the subsequent adsorption study.

Table 1 - Vibrational frequencies for $\mathrm{CO}_{2}$ molecule, as obtained from the present ab initio calculations and compared with experimental data from literature (wavenumbers in $\mathrm{cm}^{-1}$ ).

\begin{tabular}{|c|c|c|c|c|}
\hline Mode of vibration & Present work & Diu et al. [22] & Haken et al. [23] & Milloni et al. [24] \\
\hline Bending & 640 & 662 & 667 & 667 \\
\hline Symmetric stretch & 1343 & 1312 & 1337 & 1388 \\
\hline Asymmetric stretch & 2417 & 2333 & 2349 & 2349 \\
\hline
\end{tabular}




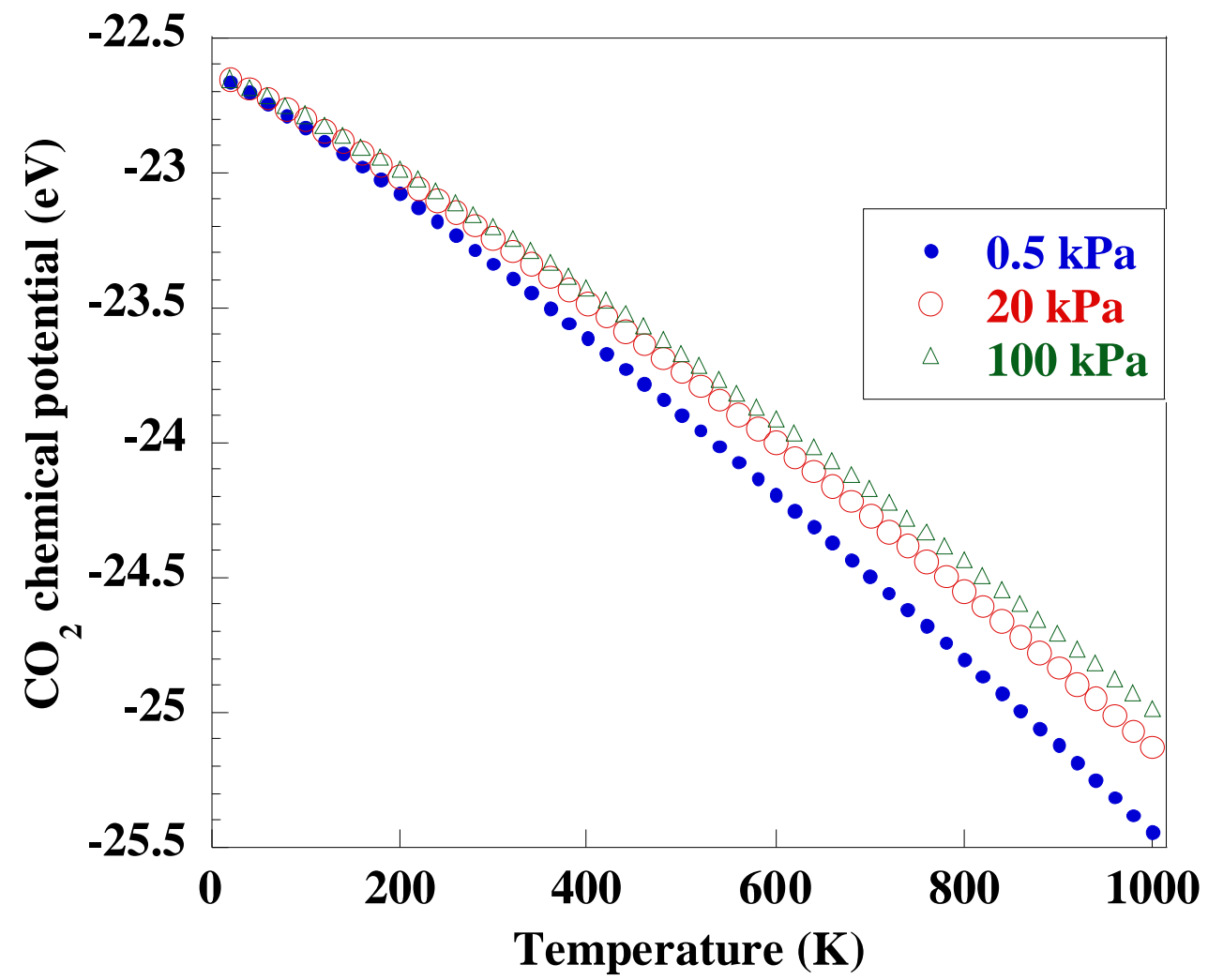

Figure $1-\mathrm{CO}_{2}$ chemical potential as a function of temperature and for various pressures, as obtained from ab initio calculations.

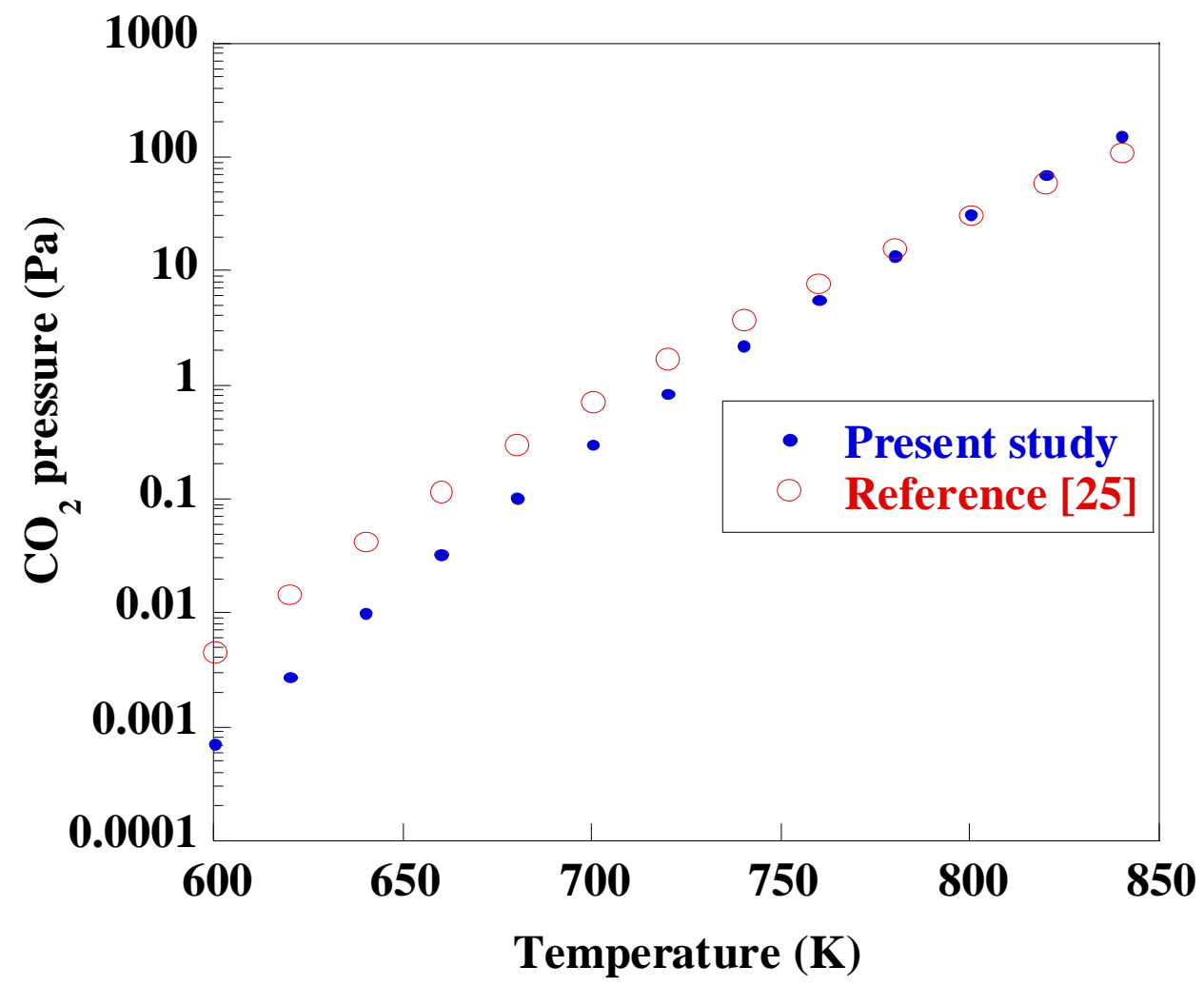

Figure 2 - Equilibrium locus for the $\mathrm{CaO}-\mathrm{CaCO}_{3}$ system, obtained in the present study and compared with standard thermodynamic data. 
As concerns the properties of the solid phases, Figure 2 shows the P-T equilibrium curve of the $\mathrm{CaO}-\mathrm{CaCO}_{3}$ system deduced from the present ab initio energy calculations, together with a comparison with standard thermodynamic data [25]. The agreement is reasonable, which further confirms the validity of our approach. The small discrepancy probably stems from the overlooking of the vibrational free energies for solid compounds in the present work. On the whole, the selected DFT framework seems adequate to investigate the properties of the solid-gas $\mathrm{CaO}-\mathrm{CO}_{2}$ adsorbed system.

\subsection{CaO clean surfaces}

Dealing with $\mathrm{CO}_{2}$ adsorption requires selecting the most relevant clean surface for this phenomenon. As the thermodynamic definition of the surface excess free energy, which is the relevant quantity in order to compare relative surface stabilities at equilibrium, involves the chemical potentials of the constituents, these solid-phase chemical potentials must be evaluated first in the context of the present $a b$ initio study. A convenient way to this aim consists in considering the point defects (PD) of bulk calcium oxide for moderate temperature and off-stoichiometry, so that defects do not interact (i.e. are independent). Therefore, within the context of non-charged defects (due to the neutralizing background imposed on the defected system by the present ab initio calculations), a point defect analysis of $\mathrm{CaO}$ was performed on a system (supercell SC) containing $2 \times 2 \times 2 \mathrm{Ca}_{4} \mathrm{O}_{4}$ unit cells, this size ensuring reasonably converged results. The $\mathrm{GC}$ energies of $\mathrm{CaO}$ point defects are displayed on Table 2 (in Kröger-Vink notation), including single interstitials, vacancies as well as Schottky and Frenkel pairs. While both kinds of Frenkel pairs are found to be unstable (spontaneous decay towards single vacancies), the Schottky defects show significant binding energies, however insufficient to ensure their persistence when lowering the temperature. The compound is clearly of single-vacancy type, with a typical defect structure at $1000 \mathrm{~K}$ given on Figure 3. Finally, Table 3 displays the corresponding calculated low-temperature chemical potentials used for surface selection. 
Table 2 - Grand canonical energies of the various point defects in $\mathrm{CaO}$ (binding energies in parentheses).

\begin{tabular}{|c|c|c|c|c|}
\hline Defect & $V_{C a}^{\times}$ & $V_{O}^{\times}$ & $C a_{i}^{\times}$ & $O_{i}^{\times}$ \\
\hline $\mathrm{E}^{\mathrm{GC}}$ & 10.072 & 11.639 & 4.887 & -0.402 \\
\hline Defect & $V_{C a}^{\times}+V_{O}^{\times}$ & $C a_{i}^{\times}+O_{i}^{\times}$ & $V_{C a}^{\times}+C a_{i}^{\times}$ & $V_{O}^{\times}+O_{i}^{\times}$ \\
\hline $\mathrm{E}^{\mathrm{GC}}$ & $16.291(-5.420)$ & $-4.949(-9.434)$ & Unstable & Unstable \\
\hline
\end{tabular}

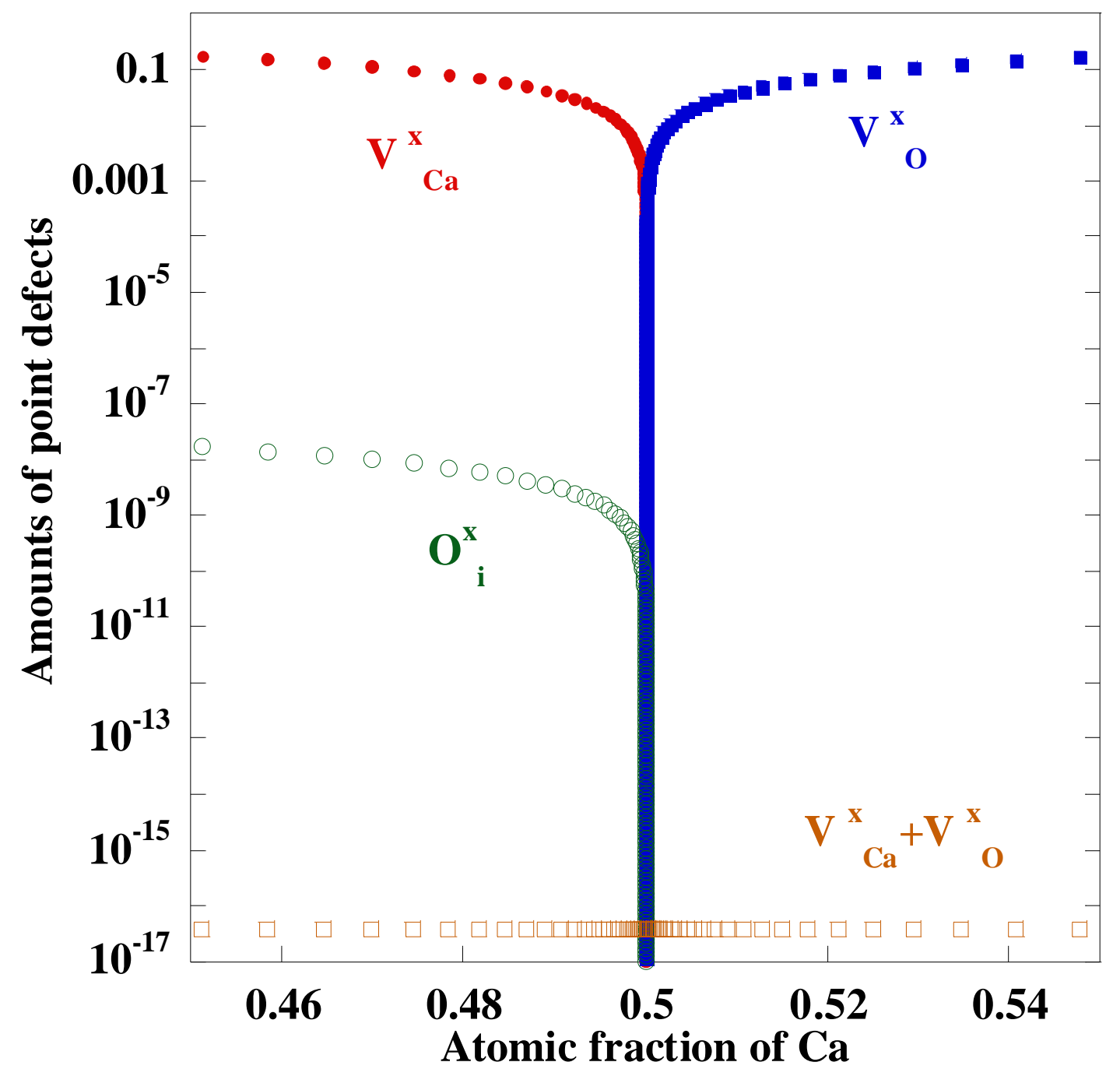

Figure 3 - Calculated point defect structure of $\mathrm{CaO}$ at $1000 \mathrm{~K}$. 


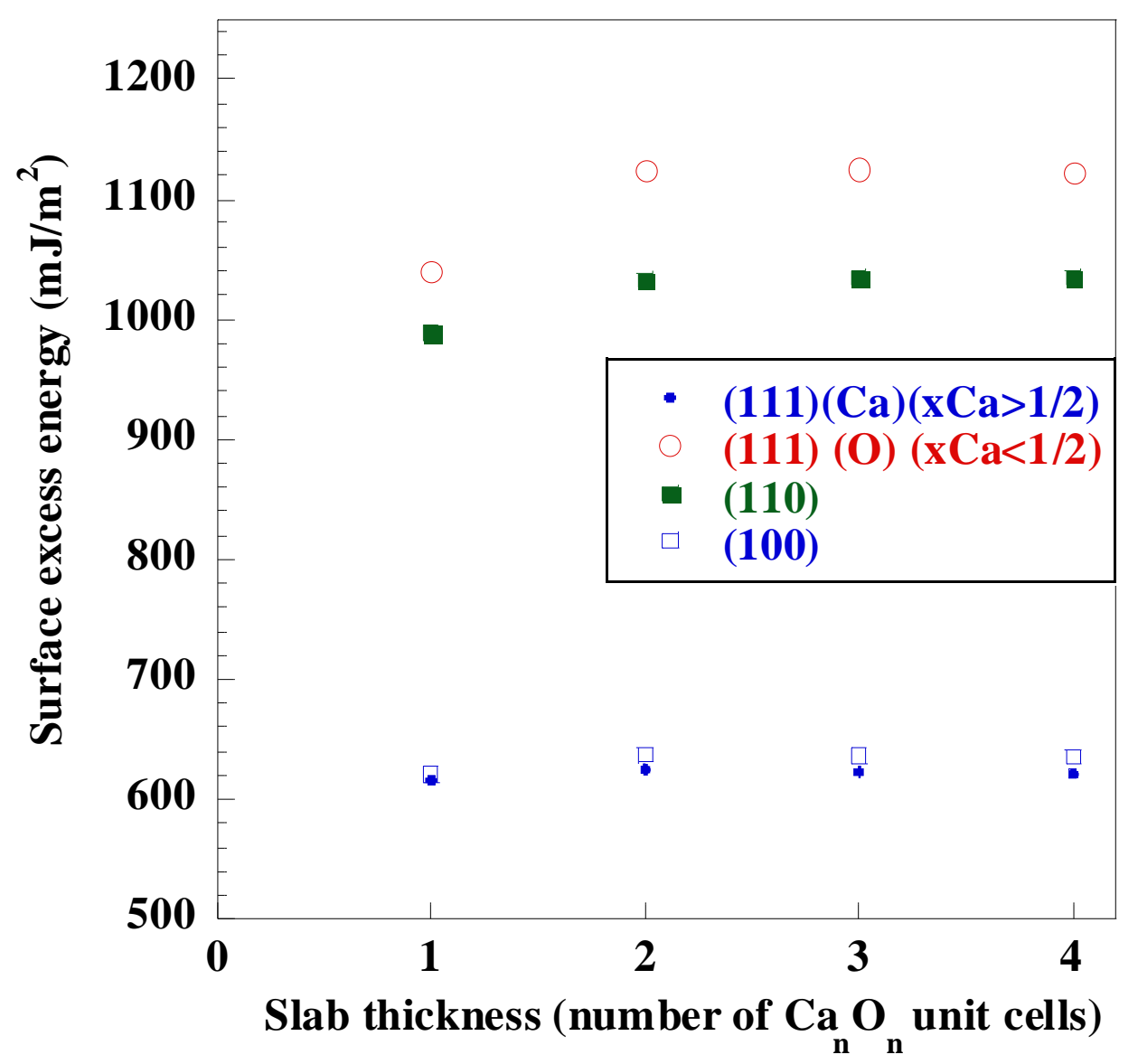

Figure 4 - Excess energy of free surfaces in $\mathrm{CaO}$ from $a b$ initio calculations performed with slabs of increasing thicknesses.

Figure 4 displays the influence of the slab thickness used for surface calculations, required to ensure the convergence of surface excess energies to within a few $\mathrm{mJ} . \mathrm{m}^{-2}$. Although all surfaces globally show similar behaviors, the convergence for the (100) surface is slightly more difficult to achieve than for other surfaces, due to the lower size of the $\mathrm{Ca}_{4} \mathrm{O}_{4}$ unit cell than for $\mathrm{Ca}_{8} \mathrm{O}_{8}$ and $\mathrm{Ca}_{12} \mathrm{O}_{12}$ (used for (110) and (111) surfaces, respectively). For all surfaces considered, a thickness of four unit cells appears to be a good compromise between accuracy and limitations in computational resources. The excess energies of these surfaces, as calculated using the previous $\mathrm{Ca}$ and $\mathrm{O}$ chemical potentials (Table 3), are presented in Table 4. The mixed character of both (100) and (110) entails a weak dependence of their energy on the off-stoichiometry, enhancing therefore the confidence of their stability, the (110) surface being significantly less stable than (100). The case of (111) is slightly more complicated, as two termination planes $(\mathrm{Ca}$ or $\mathrm{O})$ may be considered a priori. Only the $\mathrm{O}$ termination is relevant for our purpose, since the $\mathrm{CO}_{2}$ molecules cannot interact with Ca surface sites [14]. 
The preferential Ca diffusion [26], probably due to Ca vacancies, is a hint that the compound formula should be $\mathrm{CaO}_{1+\mathrm{x}}$. In this composition range, the (111) $\mathrm{O}$ energy is sufficiently high so that this surface must be discarded. From this data we decided to retain the (100) surface for the subsequent adsorption study as it presents the lower excess energy. Moreover, the energy difference between the latter and the (111) surface with Ca termination is not significant and restricted to $\mathrm{x}_{\mathrm{Ca}}>1 / 2$, whereas the (100) stability is hardly affected by offstoichiometry. This suggests (100) as the most stable $\mathrm{CaO}$ surface, and thus as the most relevant for adsorption, in agreement with previous studies on this system [11-14, 27] also focusing on the (100) surface.

Table 3 - Chemical potentials $(\mathrm{eV})$ at $\mathrm{T}=0 \mathrm{~K}$ in $\mathrm{CaO}$, from ab initio calculations and IPDA (see text for details).

\begin{tabular}{|c|c|c|}
\cline { 2 - 3 } \multicolumn{1}{c|}{} & $\mu_{\mathrm{Ca}}$ & $\mu_{\mathrm{O}}$ \\
\hline $\mathrm{x}_{\mathrm{Ca}}>1 / 2$ & -1.24 & -11.64 \\
\hline $\mathrm{x}_{\mathrm{Ca}}<1 / 2$ & -10.07 & -2.81 \\
\hline
\end{tabular}

Table 4 - Calculated excess energies $\left(\mathrm{J}^{\mathrm{m}} \mathrm{m}^{-2}\right)$ of low-index surfaces in $\mathrm{CaO}$ on each side of stoichiometry.

\begin{tabular}{|c|c|c|}
\hline Surface & $\mathrm{E}\left(\mathrm{x}_{\mathrm{Ca}}<1 / 2\right)$ & $\mathrm{E}\left(\mathrm{x}_{\mathrm{Ca}}>1 / 2\right)$ \\
\hline$(100)$ & 0.63 & 0.63 \\
\hline$(110)$ & 1.03 & 1.03 \\
\hline$(111) \mathrm{Ca}$ & 7.59 & 0.62 \\
$(111) \mathrm{O}$ & 1.13 & 8.10 \\
\hline
\end{tabular}

\section{3 $\mathrm{CO}_{2}$ adsorption}

\subsubsection{Assumption of non interacting $\mathrm{CO}_{2}$}

The first step to explore $\mathrm{CO}_{2}$ adsorption consists in supposing energetically independent molecules. As mentioned above, the properties of non interacting $\mathrm{CO}_{2}$ molecules are fully described through the GC energies relative to each orientation. These quantities have to be determined with sufficient accuracy, especially as regards the elimination of spurious 
coupling due to the periodic boundary conditions. In reason of computational limitations, only SC sizes up to $3 \times 3$ unit cells could be considered, and Table 5 indicates that convergence is reasonably achieved in these conditions. Applying these values with the above model, equation (9), for both orientations, Figure 5 (open symbols) shows the influence of pressure on the calculated $\mathrm{CO}_{2}$ coverage rates for increasing temperatures. As expected, following a typical Langmuir behavior, raising the temperature induces a decrease of the surface coverage. Although orientation 2 is always favored, higher temperatures (above $800 \mathrm{~K}$ ) correspond to a mixture of orientations, the adsorbed molecules being truly independent due to the low coverage. For lower temperatures, although the molecules can no longer be considered as isolated, the figure suggests a partitioning of $(1,2)$ orientations in proportions of $(1 / 3,2 / 3)$ as a common limit for the isotherms below $750 \mathrm{~K}$. It should however be noted that these remarks rely solely on the GC energies for type 1 and type 2 orientations, both quantities having remarkably close values. This points out the necessity to refine the approach by taking into account the interactions between adsorbed $\mathrm{CO}_{2}$.

Table 5 - Grand canonical energies $(\mathrm{eV})$ of isolated $\mathrm{CO}_{2}$ adsorbed on (100) $\mathrm{CaO}$ surface for both orientations, as a function of the supercell size within the surface plane.

\begin{tabular}{|c|c|c|c|}
\hline SC size & $1 \times 1$ & $2 \times 2$ & $3 \times 3$ \\
\hline Orientation 1 & -23.309 & -24.337 & -24.380 \\
\hline Orientation 2 & -23.632 & -24.372 & -24.412 \\
\hline
\end{tabular}
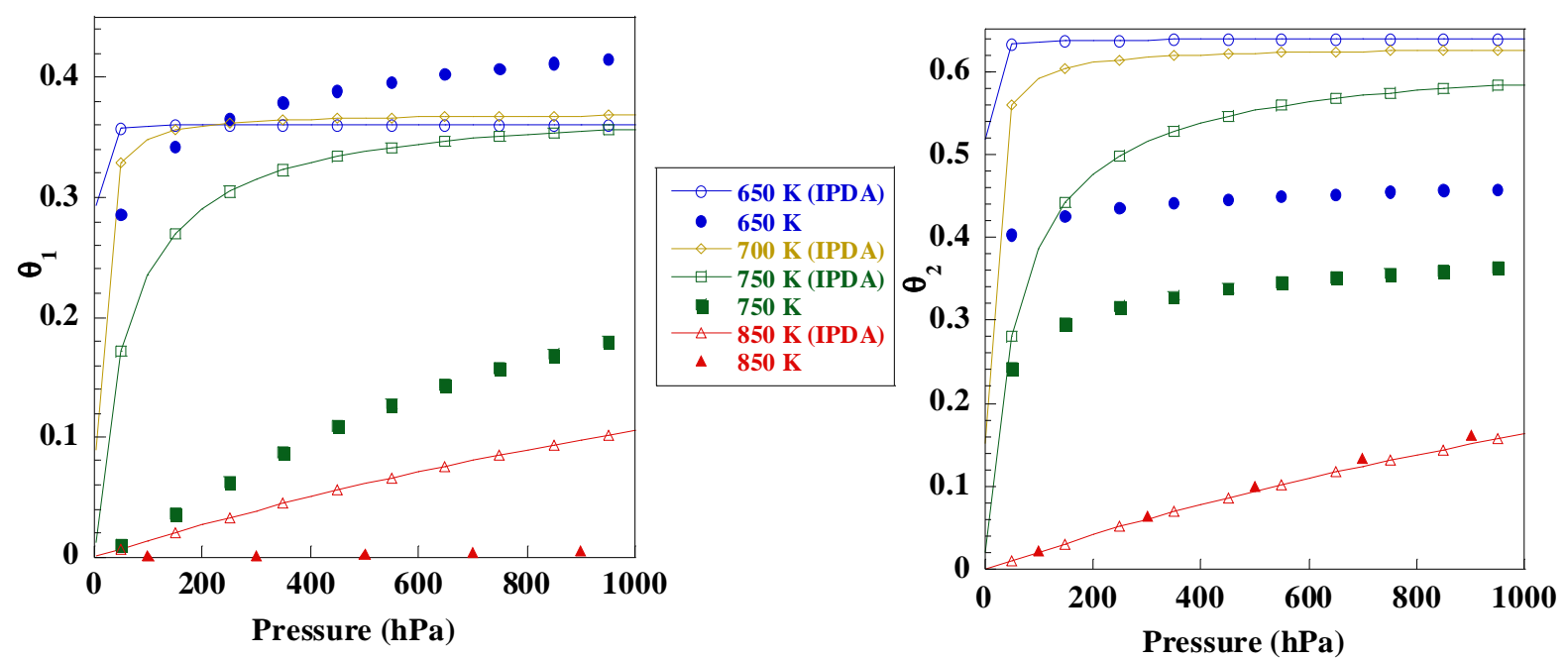

Figure 5 - Calculated influence of pressure on $\mathrm{CO}_{2}$ coverage of the $\mathrm{CaO}$ (100) surface for 
both types of orientations, supposing independent (IPDA) adsorbed molecules (open symbols) or including lateral interactions (full symbols).

\subsubsection{Influence of lateral interactions between $\mathrm{CO}_{2}$}

Within the framework of the adsorption model presented above, the main issue lies in quantifying the interaction energy $\delta E^{I P D A}\left(\theta_{1}, \theta_{2}\right)$ between $\mathrm{CO}_{2}$ molecules with arbitrary distributions of type 1 and type 2 orientations. In order to deal with this highly intricate problem, we first used ab initio calculations with a $2 \times 2 \times 4$ supercell to evaluate $\delta E^{I P D A}$ for selected configurations containing a single type of orientation and parallel molecules (no orientation degeneracy). The same numbers of symmetrically non-equivalent configurations were studied for each orientation and various coverages (Figure 6, full symbols). As expected, the energy is, strictly speaking, dependent on the configuration (as illustrated for $25 \%$ and 75 $\%$ coverages). Nevertheless, this configuration-dependent dispersion remains limited, and the study clearly reveals an increasing trend for both orientations, indicating the repulsive nature of interactions between molecules with identical orientations, the repulsion being much more pronounced for orientation 2. This clear-cut feature justifies to approximate $\delta E^{I P D A}\left(\theta_{1}, \theta_{2}=0\right) \cong \delta E_{1}$ with a $4^{\text {th }}$ order polynomial $a_{1} \theta_{1}+b_{1} \theta_{1}{ }^{4}\left(a_{1}=0.54054\right.$ and $b_{1}=$ 2.8611). For orientation 2 , a $6^{\text {th }}$ order polynomial $b_{2} \theta_{2}{ }^{6}\left(b_{2}=13.649\right)$ is best suited to model $\delta E^{I P D A}\left(\theta_{1}=0, \theta_{2}\right) \bumpeq \delta E_{2}$. The validity of the present fitting for $\delta E^{I P D A}$ was then checked on configurations including orientation degeneracy (open symbols on Figure 6). As a working expression for $\delta E^{I P D A}$, a linear interpolation was finally assumed:

$$
\delta E^{I P D A}\left(\theta_{1}, \theta_{2}\right)=\left(1-\theta_{2}\right) \delta E_{1}+\left(1-\theta_{1}\right) \delta E_{2}
$$

Although checking thoroughly this expression would be cumbersome, its validity was provided some confirmation by ab initio calculations for $\theta_{1}=\theta_{2}=1 / 8$, which showed a reasonable agreement with equation (10). Further refinement of the latter expression, through the use of an enlarged pool of ab initio data and more general fitting, would simply require supplementary computational labour, and this might constitute an interesting extension of the present work. Figure 5 (full symbols) displays the adsorption behavior including the effect of lateral interactions between molecules. The trend already mentioned for the non-interacting case is maintained, i. e. the prevalence of orientation 2 , the effect of interactions being to decrease both coverages. 


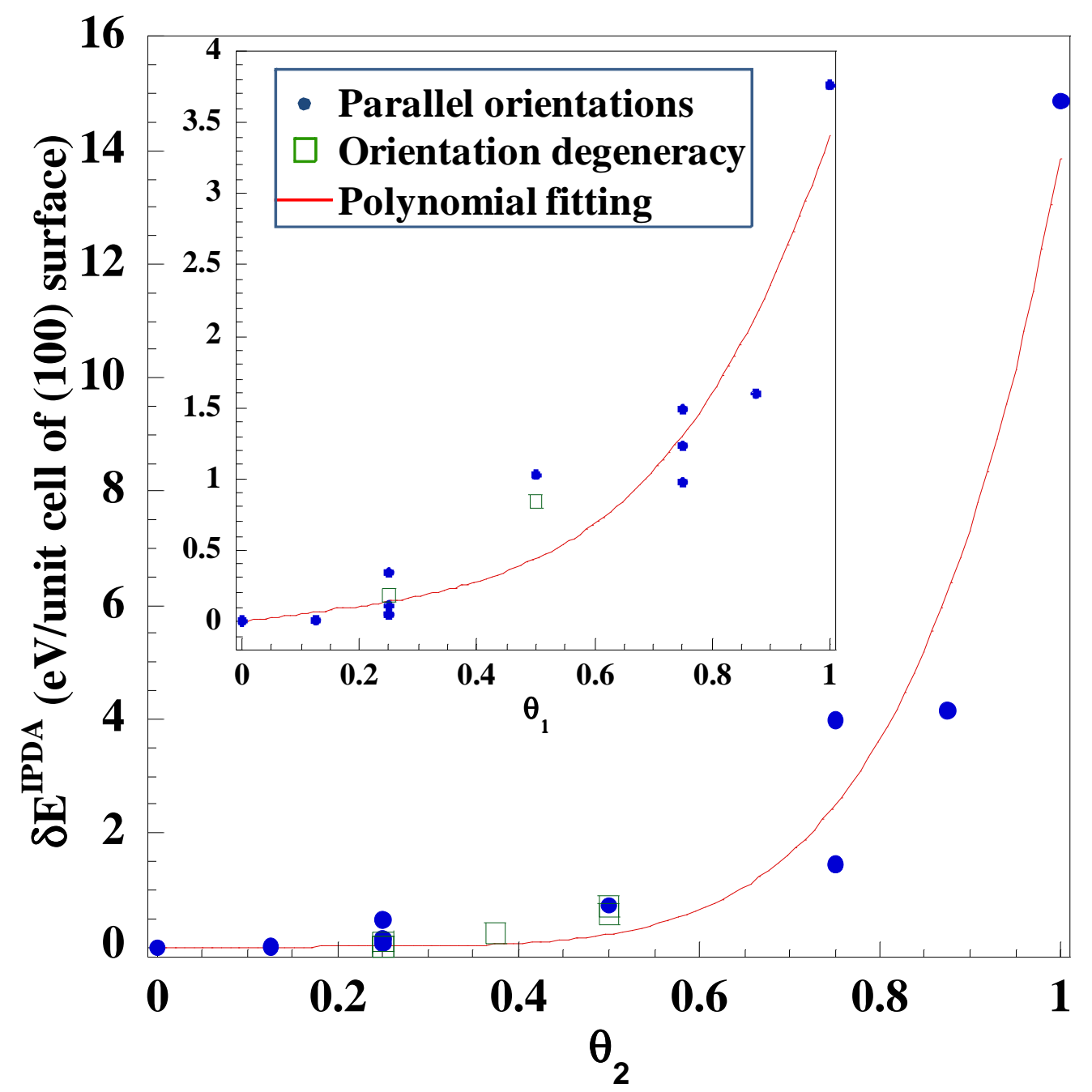

Figure 6 - Influence of surface coverage on the interaction energy between adsorbed $\mathrm{CO}_{2}$ molecules, for various configurations with parallel orientations (full symbols), including orientation degeneracy (open symbols) and fitted on polynomials (lines).

Table 6 - Calculated surface coverages for range of working conditions typical of carbonate nucleation from $\mathrm{CaO}$.

\begin{tabular}{|c|c|c|c|}
\hline $\mathrm{P}(\mathrm{kPa})$ & $\mathrm{T}(\mathrm{K})$ & 650 & 850 \\
\hline \multirow{2}{*}{2} & $\theta_{1}\left(\theta_{1}{ }^{\mathrm{IPDA}}\right)$ & $2.310^{-1}\left(3.510^{-1}\right)$ & $7.310^{-5}\left(2.810^{-3}\right)$ \\
\cline { 2 - 4 } & $\theta_{2}\left(\theta_{2}{ }^{\mathrm{IPDA}}\right)$ & $3.810^{-1}\left(6.210^{-1}\right)$ & $4.410^{-3}\left(4.310^{-3}\right)$ \\
\hline \multirow{2}{*}{30} & $\theta_{1}\left(\theta_{1}{ }^{\mathrm{IPDA}}\right)$ & $3.710^{-1}\left(3.610^{-1}\right)$ & $1.310^{-3}\left(1.510^{-1}\right)$ \\
\cline { 2 - 3 } & $\theta_{2}\left(\theta_{2}{ }^{\mathrm{IPDA}}\right)$ & $4.410^{-1}\left(6.410^{-1}\right)$ & $6.310^{-1}\left(2.410^{-1}\right)$ \\
\hline
\end{tabular}




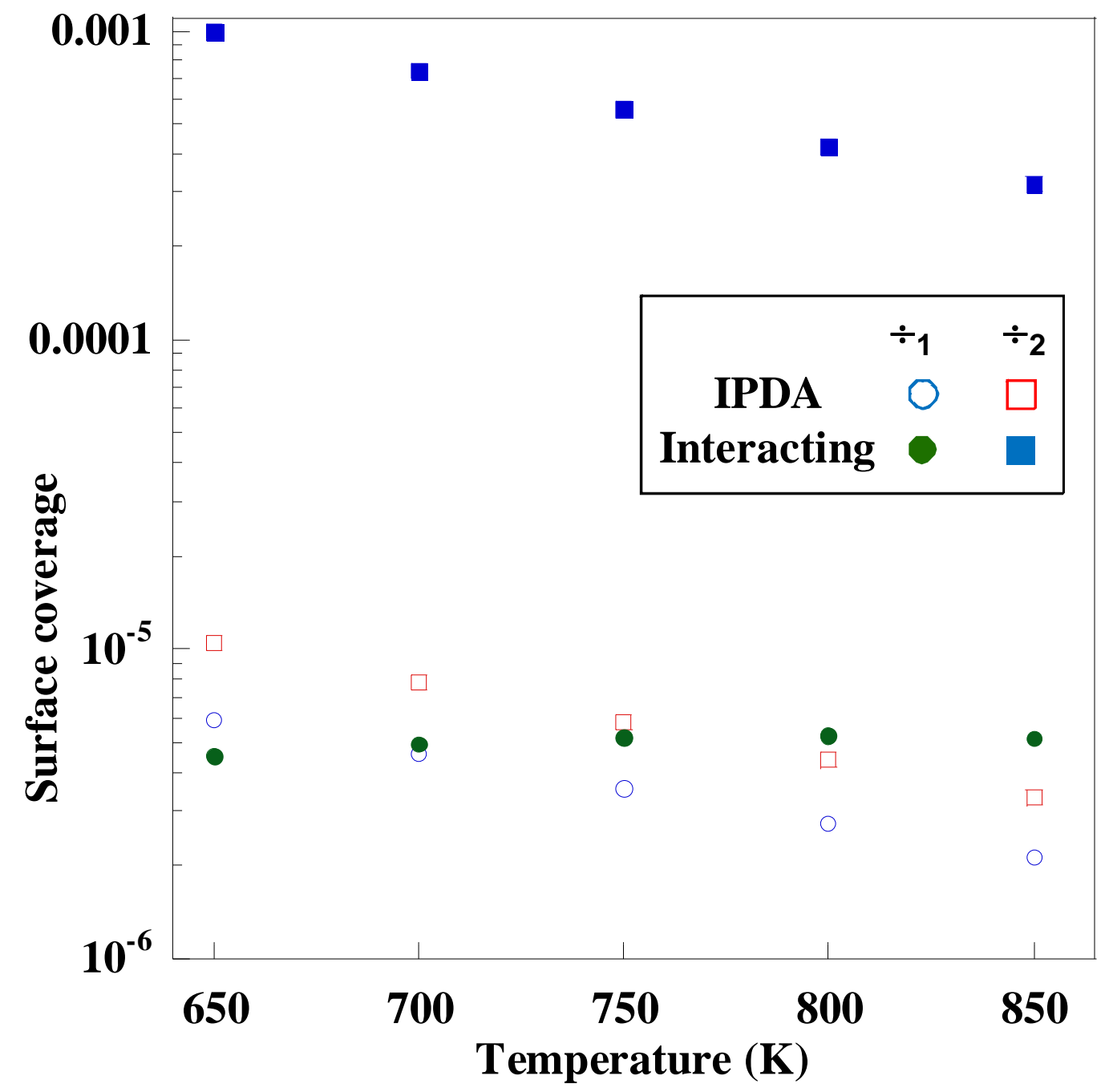

Figure 7 - Surface coverage for critical (P, T) conditions corresponding to Figure 4, within IPDA or including lateral interactions between $\mathrm{CO}_{2}$.

In order to explore the relation between the adsorption of $\mathrm{CO}_{2}$ and the $\mathrm{CaO} \leftrightarrow \mathrm{CaCO}_{3}$ phase transition, it is instructive to consider critical $(\mathrm{P}, \mathrm{T})$ conditions belonging to the equilibrium locus (Figure 2). From Figure 7, the rate of coverage for critical conditions confirms the above tendency of orientation 2 prevailing over orientation 1 in the temperature range considered. These critical coverage values being low (around $10^{-3}$ ), our results thus may seem at odds with the earlier assumption of fully covered surface [14]. However, a more recent work about carbonation of $\mathrm{CaO}$ [10] indicated that efficient working conditions for this process should rather correspond to $2-30 \mathrm{kPa}$ and $300-600^{\circ} \mathrm{C}$, namely deep within the stability domain of calcite. Considering these temperature and pressure ranges (Table 6) allows to partially reconcile our approach and previous ones, with $\mathrm{CO}_{2}$ coverages possibly approaching a full monolayer. On the whole, proposing a clear picture of the adsorbed $\mathrm{CaO}$ surface beyond 
the $\mathrm{CaO}-\mathrm{CaCO}_{3}$ equilibrium curve remains complex, since Table 6 also exhibits working conditions (at higher temperatures) consistent with low coverages. This feature, not only holds within the simple framework of non-interacting adsorbed molecules, but is maintained if lateral interactions are included. Our study therefore strongly indicates that nucleation of calcite on $\mathrm{CaO}$ surface should be a localised process, implying small clusters of $\mathrm{CO}_{2}$ molecules. It should discard the hypothesis of collective transformation of a full adsorbed monolayer.

\section{Conclusion}

As a first step towards a detailed knowledge of the nucleation mechanism of calcite on calcium oxide, the purpose of this paper was to provide a better understanding of the adsorption properties of carbon dioxide on $\mathrm{CaO}$, by means of atomic-scale ab initio calculations and thermodynamic modelings including the gas phase as well as the system of molecules adsorbed on the (100) surface. Our approach allowed to evaluate the respective contributions of the two orientations possibly adopted by $\mathrm{CO}_{2}$, including symmetry-induced degeneracies. Introducing a simplified surface energetic description in terms of noninteracting $\mathrm{CO}_{2}$ indicates that adsorbed molecules behave as a "mixture" containing both orientations with similar proportions. The level of coverage by $\mathrm{CO}_{2}$ is found to remain low, up to working conditions far beyond the oxide-calcite equilibrium locus. This approach was refined through the ab initio study of the energetics of various configurations involving adsorbed molecules in a close neighborhood, which provided a simple and reasonable picture of the interaction energy relevant for adsorption in the $\mathrm{CaO}-\mathrm{CO}_{2}$ system. This refined model confirms the conclusion of $\mathrm{CaO}$ surfaces only partially covered by $\mathrm{CO}_{2}$ in a wide domain of pressure and temperature. Our work strongly suggests that calcite formation should imply a nucleation process occurring on a localized scale, and rules out the hypothesis of collective conversion of adsorbed monolayer. Fruitful extensions of this work should be provided by taking into account the influence of other specific sites (corners, edges) on the surface, as well as the role of surface point defects on $\mathrm{CO}_{2}$ adsorption. Finally, atomic-scale experimental investigations of the properties of adsorbed $\mathrm{CO}_{2}$ would constitute an interesting complement to our work. 


\section{References}

[1] V. Nikulshina; C. Gebald, A. Steinfeld, Chemical Engineering Journal 146 (2009) 244.

[2] A. Silaban, D. P. Harrison, Chem. Eng. Comm. 137 (1995) 177.

[3] J. C. Abanades, D. Alvarez, Energy Fuels 17 (2003) 308.

[4] A. Palandri, P. Gilot, G. Prado, Journal of Analytical and Applied Pyrolysis 27 (1993) 119.

[5] V. Bouineau, M. Pijolat, M. Soustelle, J. Europ. Ceram. Soc. 18 (1998) 1319.

[6] J. Khinast, G. F. Krammer, C. Brunner, G. Staudinger, Chemical Engineering Science 51 (1996) 623.

[7] F.García-Labiano, A. Abad, L.F. de Diego, P. Gayán, J; Adánez, Chemical Engineering Science 57 (2002) 2381.

[8] B. D. Soares, C. E. Hori, C. E. A. Batista, H. M. Henrique, Advanced Powder Technology, Materials Science Forum 591-593 (2008) 352.

[9] S. K. Bathia, D. D. Perlmutter, AIChE J. 29 (1983) 79.

[10] L. Rouchon, L. Favergeon, M. Pijolat, to be submitted to PCCP.

[11] F. Voigts, F. Bebensee, S. Dahle, K. Volgmann, W. Maus-Friedrichs, Surface Science 603 (2009) 40.

[12] D. Ochs, B. Braun, W. Maus-Friedrichs, V. Kempter, Surface Science 417 (1998) 406.

[13] W. F. Schneider, J. Phys. Chem. B 108 (2004) 273.

[14] E. Kadossov, U. Burghaus, J. Phys. Chem. C 112 (2008) 7390.

[15] Z. Du, N. L. Allan, J. A. Purton, R. A. Brooker, Geochimica et Cosmochimica 72 (2008) 554 .

[16] D.K. Fisler, J. D. Gale, R. T. Cygan, American Mineralogists 85 (2000) 217.

[17] A. L. Rohl, K. Wright, J. D. Gale, American Mineralogists 88 (2003) 921.

[18] R. Ditchfield, W. J. Hehre, J. A. Pople, J. Chem. Phys. 54 (1971) 724.

[19] F. J. van Duijneveldt, IBM Res. Rep. RJ (1971) 945

[20] P. S. Bagus, F. Illas, J. Chem. Phys. 96 (1992) 8692

[21] P. S. Bagus, K. Hermann, C. W. Bauschlicher, J. Chem. Phys, 80 (1984) 4378

[22] B. Diu, B., D. Lederer, B. Roulet, "Elements de physique statistique", Hermann (2006)

[23] H. Haken, H. C. Wolf, "Molecular Physics and Elements of Quantum Chemistry", 2nd

Edition, Springer (2004)

[24] P. W. Milloni, J. H. Eberly, "Laser Physics” Wiley (2010)

[25] Thermochemical Properties of Inorganic Substances, $2^{\text {nd }}$ ed, Vol. 1 and 2 Springer (1991)

[26] P. Kofstad "High temperature oxidation of metals" Wiley (1966)

[27] G. Pachioni, J. M. Ricart, F. Illas, J. Am. Chem. Soc.116 (1994) 10152 